\title{
Trends and determinants of contraceptive method choice
}

\section{among women aged 15-24 years in Kenya [version 1; peer review: 2 approved with reservations]}

\author{
Wambui Kungu(D), Alfred Agwanda, Anne Khasakhala
}

Population Studies and Research Institute, University of Nairobi, Nairobi, +254, Kenya

V1 First published: 19 Mar 2020, 9:197

https://doi.org/10.12688/f1000research.22481.1

Latest published: 19 Mar 2020, 9:197

https://doi.org/10.12688/f1000research.22481.1

\section{Abstract}

Background: Studies show a gap in addressing the reproductive health goals of younger women whose inconsistent use of contraception is high in spite of their great need for it. The women aged 15-24 present high potential for unintended pregnancy and increase the challenge for retention of users which is key in maintaining and pushing up the current gains in contraceptive prevalence rate (CPR).

Objective: The objective of the study was to examine trends in contraceptive method choice for young women aged 15-24 years using modern methods and to determine factors associated with their choices.

Methods: The study used data from KDHS of 2003, 2008/9 and 2014 in descriptive analysis and logistic regression to determine the socioeconomic variables that influence the choice of contraceptive methods for young women.

Results: Results showed a general shift in use towards long term modern contraceptives with the shift being more pronounced among young women with primary education, from rural areas, lower wealth households, and low contraceptive use regions. Women with secondary education and higher wealth status are shifting towards short term methods.

Findings confirmed socio-demographic factors of age, education, wealth status and type of region as predictors of contraceptive use. Conclusions: Contraceptive information and services should be enhanced for young women to make informed choices concerning their reproductive and sexual health to enable them complete school and transition to colleges to acquire relevant skills that will make them optimally productive and lead Kenya to achieving the demographic dividend.

Keywords

Trends, Determinants, Contraception Method Choice, 15-24, Kenya

\section{Open Peer Review}

Approval Status? ?

1

version $1 ?$ ?

19 Mar $2020 \quad$ view view

1. John Cleland ID, London School of

Hygieneand Tropical Medicine, London, UK

2. Jen Sothornwit ID, Khon Kaen University,

Khon Kaen, Thailand

Any reports and responses or comments on the article can be found at the end of the article. 
This article is included in the Sociology of

Health gateway.

Corresponding author: Wambui Kungu (buikungu@yahoo.com)

Author roles: Kungu W: Conceptualization, Data Curation, Formal Analysis, Methodology, Resources, Software, Validation, Visualization, Writing - Original Draft Preparation, Writing - Review \& Editing; Agwanda A: Methodology, Supervision, Validation, Writing - Review \& Editing; Khasakhala A: Methodology, Supervision, Validation, Writing - Review \& Editing

Competing interests: No competing interests were disclosed.

Grant information: The author(s) declared that no grants were involved in supporting this work.

Copyright: (c) 2020 Kungu W et al. This is an open access article distributed under the terms of the Creative Commons Attribution License , which permits unrestricted use, distribution, and reproduction in any medium, provided the original work is properly cited.

How to cite this article: Kungu W, Agwanda A and Khasakhala A. Trends and determinants of contraceptive method choice among women aged 15-24 years in Kenya [version 1; peer review: 2 approved with reservations] F1000Research 2020, 9:197 https://doi.org/10.12688/f1000research.22481.1

First published: 19 Mar 2020, 9:197 https://doi.org/10.12688/f1000research.22481.1 


\section{Introduction}

Kenya has invested considerable resources towards improving adolescent sexual reproductive health (ASRH) and has in place the 2015 National Adolescent Sexual Reproductive Health (NASRH) Policy; however, the rates of teenage pregnancies do not reflect these heavy investments and are a matter of public health and social concern. Teenage pregnancy rates have plateaued for over a decade and have persisted at $20 \%$ between 2003 and $2014^{1-3}$.

More than 10,000 Kenyan girls quit school every year due to unintended pregnancies and more than 10 percent of births in Kenya occur to girls aged 15-19 years ${ }^{4}$. Unintended pregnancies among teenagers are linked to poor health outcomes, which include sexually transmitted infections, unsafe abortion, miscarriages, stillbirths and complications during births that can lead to infant and/or maternal deaths. There is also rapid-repeat pregnancy, which is linked to greater risks of morbidity and mortality in mothers and new-borns as well as poor mental health ${ }^{5}$.

The Kenya Demographic and Health Survey (KDHS) 2014 revealed critical facts about adolescents in Kenya. One out of every three (30\%) adolescent girls reported having had sex while the average age at which adolescent girls had their first child was 17 years and $12 \%$ of the girls were already in a relationship. Most sexually active 15-19-year-olds do not use contraception and only about 50\% of those on contraception use it consistently with $14 \%$ of them being ambivalent about pregnancy. As many as $90 \%$ of unmarried sexually active adolescent girls reported not wanting to get pregnant in the next two years but only 43 percent were using a method to prevent pregnancy. Average unmet need for family planning for the group was $21 \%$ against the national average of $18 \%{ }^{1,6}$. Several interventions to address ASRH needs have been put in place but the median age at first birth continues to decrease.

Kenya has a very youthful population with the 15-24-yearold age cohort constituting about $30 \%$ of the population of 47 million $^{7}$. The 15-24-year-old young women take about $15 \%$ which comes to 7 million. With the economic growth far below the desired $10 \%$ per annum, this group is critical to economic development but for them to be substantially productive the problems surrounding them have to be comprehensively addressed ${ }^{8}$.

Demographic dividend has been proposed as a viable solution to economic challenges faced by developing countries. Kenya's demographic window is expected to open in 2038 and it could achieve demographic dividend by 2050 if it invests in the huge youth population and especially the adolescents. Demographic dividend modelling shows Kenya can attain $\$ 4,595$ in GDP per capita by 2050 if it makes strategic investments against $\$ 896$ if it maintains the status quo. This would mean a staggering fivefold economic growth whose achievement, family planning can accelerate ${ }^{9,10}$.

Also, improved access to reproductive health has been identified as critical in the process of development in Sustainable Development Goal (SDG) 3.7 ${ }^{11}$. Adolescent and young women childbearing is linked with lower educational achievement and could lead to a cycle of poverty and hinder achievement of demographic dividend. Meeting the contraception needs of adolescent and youth to prevent unintended pregnancies should thus be a priority ${ }^{12}$.

The Health Act of 2017 and constitution of Kenya have enshrined the right of every woman to safe, affordable, effective, and acceptable contraception services ${ }^{13}$. FP2020 has issued the Global Consensus Statement to expand contraceptive options for adolescents and youth and set higher family planning targets ${ }^{14}$. Family planning documents in Kenya advocate for promotion of long acting reversible contraception (implants and IUD) as safe, convenient and highly effective methods.

KDHS data shows the 15-24 age group taking a sizeable share of the modern method mix in Kenya among all users of reproductive age with $15 \%$ pill users, $8 \%$ of IUD use, $18 \%$ implants use and $24 \%$ injection use ${ }^{1}$. It also shows shifting popularity from injections to implants for the young women, but correct and consistent use remains a challenge and unintended pregnancies prevail ${ }^{5}$. Data is constantly needed to monitor the success of the many policy and program efforts towards effective reproductive health programs for youth.

Poverty is a major contributing factor to teenage pregnancies with girls from poor households more exposed to the risk of early childbearing ${ }^{8}$. Evidence has shown that without contraception, more than $90 \%$ sexually active young women get pregnant within a year ${ }^{15}$. The leading reason for adolescents' delay or for not obtaining contraceptive services is apprehension on confidentiality and side effects.

In Kenya, 22\% of unintended pregnancies end up in dangerous abortions for adolescents because they mostly abort during the second trimester after late discoveries of the pregnancies. Adolescents below 19 years make up 20\% of women seeking post-abortion care services in health facilities and $50 \%$ admissions from severe complications ${ }^{16,17}$. There is urgent need to expand access to safe and affordable reproductive health care and options especially for the more vulnerable young women of lower education and economic status who procure unsafe abortions more ${ }^{18}$.

Evidence has shown increased use of contraception is a primary factor in reduction of adolescent fertility and births rates ${ }^{19}$. Comprehensive sexuality education (CSE) and integrated youth friendly services have also shown success when well implemented but youth centres and peer education have not been effective $^{20}$. Providing contraceptive information, counselling and services and the use Larcs has been found useful to encourage new acceptors of contraception among nulliparous young women. LARCs are 99\% effective if correctly used and have several non-contraceptive benefits like reducing menstrual flow and pain and thus endometriosis.

To achieve demographic dividend, a country must undergo a demographic transition which brings about lower birth and death rates through investments in family planning. Significant 
declines in fertility can be reaped from a high contraceptive use momentum that young women can generate. A slower population growth can also be achieved if age at first birth is delayed for most of these women. A huge young population represents great economic potential and investments in their health and education can stimulate new economic opportunities ${ }^{21}$.

Previous studies in Kenya have identified socio economic factors such as education and wealth as significant on the use of contraception ${ }^{22,23}$. Choice and continued use of a method is influenced by socio-economic factors hence the choice of explanatory variables ${ }^{24}$. This study attempted to provide a current information base on how contraceptive use among 15-24 years old girls in Kenya has evolved from 2003 to 2014 with a view to providing evidence which could form a basis to increase modern contraceptive use among them.

The main objective of the study was to examine factors that influence the choice of contraceptive methods for young women 15 to 24 years old.

\section{Methods}

Data sources

This study analysed secondary data from the Kenya Demographic and Health Surveys of 2003, 2008/9 and 2014, which contained detailed contraceptive calendars for all interviewed women aged 15 to 49 years. The study was based on the samples of all 15-to-24-year-old women, whether married or single, who reported current use of modern contraception within the five years prior to the three surveys. It excluded those who were not using a main modern contraceptive at the time of the each KDHS. Data was specifically obtained from the variables on current method used, age, education, residence, wealth and region.

\section{Data analysis}

Data analysis was performed using SPSS version 22. The study started with obtaining frequencies for each of the methods to obtain a trend analysis of the main methods of contraception used by the young women, namely the Pill, IUD, Implants, Injection and Condoms for the three data sets. Afterwards, young women contraceptive users were profiled using cross-classification analysis on socio demographic variables of age, education, wealth status, place of residence and type of region to provide trends of contraceptive method choice within the period of study. This refers to arranging the data into classes according to the variables. Pearson's Chi square test was used to determine existence of any significant relationships between the dependent variable (contraceptive method choice) and the independent socio demographic variables.

The dependent variable was dichotomous, hence binary logistic regression was used to determine the net effects of the independent variables (age, education, wealth status and type and region of residence) on method choice.

Contraceptive method was recoded as either short term (pills, condoms) or long term (injection, IUD, implants), while level of education was recoded into two categories (primary and secondary/higher). Household wealth status was recoded into three tertiles of lower (lowest, and second lowest), middle (middle) and higher (fourth quintile and highest) while region was recoded into two categories of high contraceptive use (Nairobi, Central and Eastern) and lower contraceptive use (the rest of the regions).

\section{Results}

Background characteristics of the study population

The first objective of the study was 'to establish the profiles of 15-24-year-old modern contraceptive users' over the years 2003 to 2014. The following Table 1 presents the background characteristics of the study population who reported using a main modern method in each KDHS.

The majority of the study group in 2003 were in the 20-24 age group $(76 \%)$; this proportion increases to over $80 \%$ in 2008/09 and 2014. There is also a trend of rising education levels: in 2003, 68\% had received only primary education, which reduces to $51 \%$ by 2014 ; those with secondary education increased from $32 \%$ in 2003 to $49 \%$ in 2014 . The majority

Table 1. Background Characteristics of the 15-24 Women using modern methods of contraception, 2003 to 2014

\begin{tabular}{|l|l|l|l|}
\hline & \multicolumn{3}{|c|}{ DHS year } \\
\hline & $\mathbf{2 0 0 3}$ & $\mathbf{2 0 0 8 / 0 9}$ & $\mathbf{2 0 1 4}$ \\
\hline Total respondents & 374 & 484 & 2730 \\
\hline Age, years & & & \\
\hline 15-19 & 24 & 17.8 & 19.6 \\
\hline 20-24 & 76 & 82.2 & 80.4 \\
\hline Education & & & \\
\hline Primary & 67.8 & 62.3 & 50.8 \\
\hline Secondary and above & 32.2 & 37.7 & 49.2 \\
\hline Residence & & & \\
\hline Rural & 63.1 & 62.8 & 51.2 \\
\hline Urban & 36.9 & 37.2 & 48.8 \\
\hline Wealth Status & & & \\
\hline Lower & 19.9 & 23.4 & 29.9 \\
\hline Middle & 18.3 & 16.7 & 20.9 \\
\hline Higher & 61.8 & 60 & 49.1 \\
\hline Region & & & \\
\hline Low contraceptive uptake & 56.3 & 54.6 & 58 \\
\hline High contraceptive uptake & 43.7 & 45.4 & 42 \\
\hline Method & & & \\
\hline Short term & 39.5 & 40 & 26.6 \\
\hline Long term & 60.5 & 60 & 73.4 \\
\hline & & \\
\hline
\end{tabular}


of surveyed individuals (63\%) were living in rural areas between 2003 and 2008/09, but this figure drops to $51 \%$ in 2014. Urban areas accommodated $37 \%$ in 2003 and 2008/09 and $49 \%$ in 2014.

On wealth status in 2003 and 2008/09, 20\% were in the lower category, $18 \%$ in middle and $60 \%$ in higher. In 2014, the higher category reduced to $49 \%$, middle increased to $21 \%$ and lower to $30 \%$. The emerging trend is increasing users of contraception are of lower wealth status. For region, those from regions with low contraception uptake were the majority at $55-58 \%$, while regions of high contraceptive use made up $42-45 \%$ of the surveyed. Regarding the contraceptive methods used, the majority (60\%) reported using long-term methods in 2003 and 2008/09, a figure that increased to $76 \%$ in 2014; use of short-term methods dropped from $40 \%$ (2003) to $27 \%$ (2014).

The general profile of modern contraceptive users among the group is that of women with primary education, living in urban areas, from higher wealth households and regions of low contraception.

\section{Trends in contraceptive method choice}

The section addresses the second objective, 'to establish the trends in contraceptive method choice for young women', 15-24 in Kenya from 2003 to 2014. Further analysis established shares of use for the Pill, Condom, Injection, IUD and Implants presented in the following figure.

As seen in Figure 1, the main method of contraception was injection with a share of $54-58 \%$ in the three data sets. Its share increased slightly between 2003 and 2008/09 from 56\% to 58\% then reduced to $54 \%$ in 2014 . The pill was second most common in $2003(23 \%)$ but declined to fourth (11\%) in 2014.
Condom use increased from $17 \%$ in 2003 to the second largest share in $2008 / 09$ at $24 \%$ but fell to third position in 2014 , below implants. Implants were fourth between 2003 and 2008/09 with a 2-3\% share but between 2008/09 and 2014, had a huge upsurge of 16 percentage points from $1.9 \%$ to $17.7 \%$ to move to second position after injection. The IUD had a very low share of between $0.4 \%$ and $2 \%$.

\section{Differentials of contraceptive method choice}

The majority of users of long-term contraceptive methods had primary education and lived in rural areas and in regions of lower contraception (Table 2). On wealth status, majority were in the middle category in 2003 but in 2008/09 and 2014, bigger proportions were of lower wealth. Users of short-term methods had secondary education, were wealthy and lived in urban areas mostly in regions of high contraception.

\section{Logistic regression results}

Logistic regression results are presented Table 3. They respond to the third objective of the study, 'to identify determinants of contraceptive choice among 15-24 year olds.

Results show that age and education were significantly associated with method choice in 2003. Age was positively associated with choosing a long-term method for a 20-24-yearold woman, being two and a half times more likely than for a 15-19 woman. Education was negatively associated with choosing a long-term method, with women with secondary education being $60 \%$ more likely to choose short-term methods than those with primary education.

In 2008/09, age, education and region were significantly associated with choosing a long-term method, with region and age having positive relationships while education continued to exhibit a negative relationship. For age, there was an almost $100 \%$

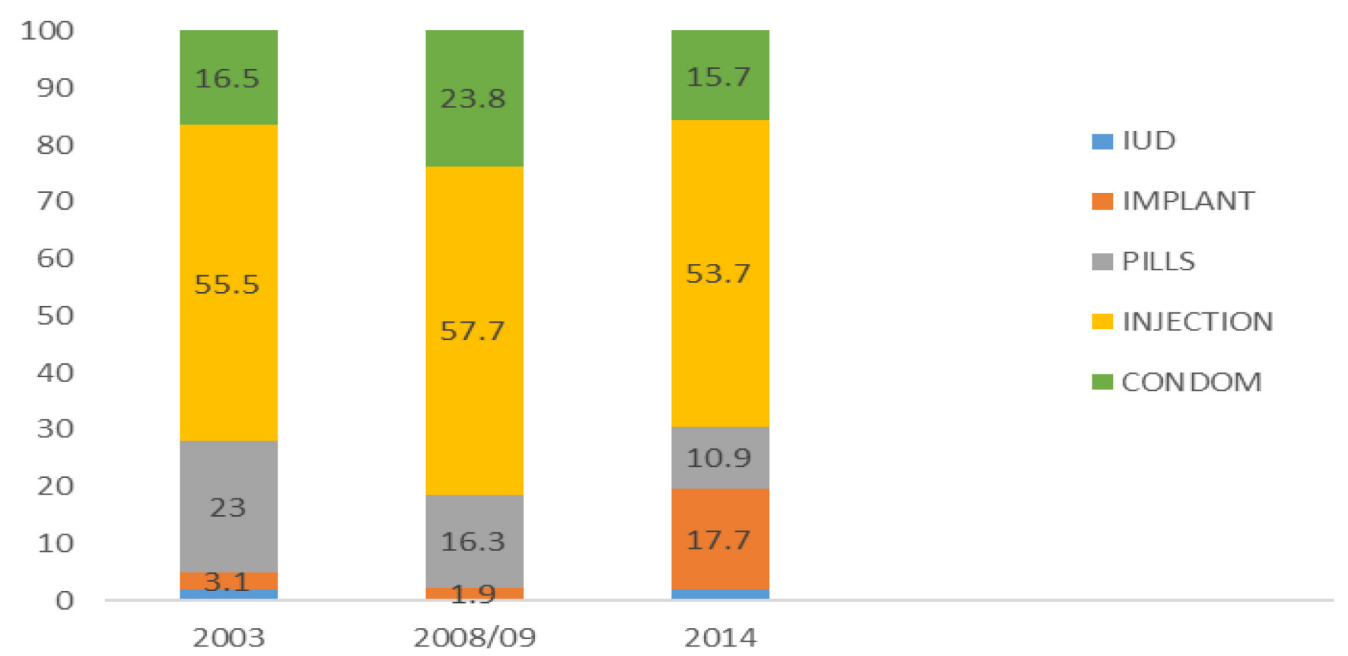

Figure 1. Trends in Contraceptive Method Choice in Percentage for Women Aged 15-24, 2003-2014. Source: KDHS Data. 
Table 2. Differentials of contraceptive method choice by various background characteristics, 2003 to 2014.

\begin{tabular}{|c|c|c|c|c|c|c|}
\hline \multirow[t]{3}{*}{ Variable } & \multicolumn{6}{|c|}{ DHS Year } \\
\hline & \multicolumn{2}{|c|}{$2003(N=374)$} & \multicolumn{2}{|c|}{$2008 / 09(N=484)$} & \multicolumn{2}{|c|}{$2014(N=2730)$} \\
\hline & Short term, \% & Long term, \% & Short term, \% & Long term, \% & Short term, \% & Long term, \% \\
\hline \multicolumn{7}{|l|}{ Age } \\
\hline $15-19$ & 54.4 & 45.6 & 52.9 & 47.1 & 33.1 & 66.9 \\
\hline \multirow[t]{2}{*}{ 20-24 } & 34.9 & 65.1 & 37.2 & 62.8 & 25 & 75 \\
\hline & \multicolumn{2}{|c|}{$X^{2}=10.963$ df $=1$ Sig $=0.001$} & \multicolumn{2}{|c|}{$X^{2}=7.321 \mathrm{df}=1$ Sig $=.007$} & \multicolumn{2}{|c|}{$X^{2}=14.426 \mathrm{df}=1 \mathrm{Sig}=.000$} \\
\hline \multicolumn{7}{|l|}{ Education } \\
\hline Pry & 36 & 64 & 30.5 & 69.5 & 16.8 & 83.2 \\
\hline \multirow[t]{2}{*}{$\mathrm{Sec}+$} & 46.7 & 53.3 & 56 & 44 & 36.7 & 63.3 \\
\hline & \multicolumn{2}{|c|}{$X^{2}=3.901 \mathrm{df}=1 \mathrm{Sig}=.048$} & \multicolumn{2}{|c|}{$X^{2}=30.941$ df $=1$ Sig $=0.000$} & \multicolumn{2}{|c|}{$X^{2}=138.305$ df $=1$ Sig $=0.000$} \\
\hline \multicolumn{7}{|l|}{ Residence } \\
\hline Rural & 37.3 & 62.7 & 38.5 & 61.5 & 19.8 & 80.2 \\
\hline \multirow[t]{2}{*}{ Urban } & 43.1 & 56.9 & 42.8 & 57.2 & 33.7 & 66.3 \\
\hline & \multicolumn{2}{|c|}{$X^{2}=1.212 \mathrm{df}=1 \mathrm{Sig}=0.271$} & \multirow[t]{2}{*}{$X^{2}=0.867$ df $=1$} & \multirow[t]{2}{*}{ Sig $=0.352$} & \multicolumn{2}{|c|}{$X^{2}=67.282 \mathrm{df}=1 \mathrm{Sig}=0.000$} \\
\hline \multicolumn{5}{|l|}{ Wealth Status } & & \\
\hline Lower & 41.9 & 58.1 & 33.6 & 66.4 & 16.2 & 83.8 \\
\hline Middle & 30.9 & 69.1 & 38.3 & 61.7 & 21.7 & 78.3 \\
\hline \multirow[t]{2}{*}{ Higher } & 41.3 & 58.7 & 43.1 & 56.9 & 35 & 65 \\
\hline & $X^{2}=2.603 \mathrm{df}=2$ & Sig $=0.272$ & $X^{2}=3.173 \mathrm{df}=2$ & Sig $=0.205$ & $X^{2}=101.386 \mathrm{df}$ & $=2$ Sig $=0.000$ \\
\hline \multicolumn{7}{|l|}{ Region } \\
\hline Low contraceptive uptake & 38.6 & 61.4 & 50.6 & 49.4 & 21.1 & 78.9 \\
\hline \multirow[t]{2}{*}{ High contraceptive uptake } & 40.9 & 59.1 & 27.4 & 72.6 & 34.3 & 65.7 \\
\hline & \multicolumn{2}{|c|}{$X^{2}=0.201 \mathrm{df}=1 \mathrm{Sig}=0.654$} & \multicolumn{2}{|c|}{$X^{2}=26.800$ df $=1$ Sig $=0.000$} & \multicolumn{2}{|c|}{$X^{2}=59.363 \mathrm{df}=1 \mathrm{Sig}=0.000$} \\
\hline
\end{tabular}

Table 3. Results of logistic regression of contraceptive method choice in Kenya 2003-2014 for women aged 15-24.

\begin{tabular}{|c|c|c|c|c|c|c|c|c|c|}
\hline \multirow[t]{2}{*}{ Variable } & \multicolumn{3}{|c|}{$2003(\mathrm{~N}=374)$} & \multicolumn{3}{|c|}{$2008 / 09(N=484)$} & \multicolumn{3}{|c|}{$2014(\mathrm{~N}=2730)$} \\
\hline & B & SE & EXP B & B & SE & EXP B & B & SE & EXP B \\
\hline \multicolumn{10}{|l|}{ Age } \\
\hline $15-19$ (ref) & .000 & & 1.000 & .000 & & 1.000 & .000 & & 1.000 \\
\hline $20-24$ & .918 & .255 & $2.503^{* * *}$ & .677 & .255 & $1.967^{*}$ & .569 & .111 & $1.766^{* * *}$ \\
\hline \multicolumn{10}{|l|}{ Education } \\
\hline Pry (ref) & .000 & & 1.000 & .000 & & 1.000 & .000 & & 1.000 \\
\hline Sec+ & -.519 & .240 & $.595^{*}$ & -1.130 & .215 & $.323^{* * *}$ & -.880 & .097 & $.415^{\star * *}$ \\
\hline \multicolumn{10}{|l|}{ Residence } \\
\hline Rural (ref) & .000 & & 1.000 & .000 & & 1.000 & .000 & & 1.000 \\
\hline Urban & -.038 & .270 & .963 & -.082 & .257 & .921 & -.204 & .113 & .816 \\
\hline \multicolumn{10}{|l|}{ Wealth } \\
\hline Lower (ref) & .000 & & 1.000 & .000 & & 1.000 & .000 & & 1.000 \\
\hline Middle & .387 & .362 & 1.472 & -.023 & .328 & .977 & -.105 & .144 & .900 \\
\hline Higher & -.025 & .315 & .975 & .061 & .302 & 1.063 & -.505 & .136 & $.604^{* * *}$ \\
\hline \multicolumn{10}{|l|}{ Region } \\
\hline Low (ref) Contraceptive & .000 & & 1.000 & .000 & & 1.000 & .000 & & 1.000 \\
\hline High Contraceptive & -.136 & .222 & .873 & 1.003 & .204 & $2.727^{* * *}$ & -.436 & .095 & $.647^{* * *}$ \\
\hline \multicolumn{10}{|l|}{ Model } \\
\hline-2 Log Likelihood $\pi^{2}$ & \multicolumn{3}{|c|}{481.886} & \multicolumn{3}{|c|}{587.280} & \multicolumn{3}{|c|}{2921.715} \\
\hline Model X² & \multicolumn{3}{|c|}{19.440} & \multicolumn{3}{|l|}{64.761} & \multicolumn{3}{|c|}{241.648} \\
\hline
\end{tabular}


increase in the odds of a 20-24 woman choosing a long-term method when compared with a 15-19-year-old. Conversely, there was a great decrease in the odds of using a long-term method as the level of education rose. Secondary-educated women were $70 \%$ less likely to choose long-term methods relative to those with primary education suggesting an inverse relationship. For region, the odds of a woman from a region of high contraception uptake choosing a long-term method were almost three times greater than for a woman from a region of low contraception uptake.

In 2014, four variables (age, education, wealth status and region) emerged as significant predictors of contraceptive method choice. Age was positively associated while education, region and wealth status were negatively associated. On age, 20-24-year-old women were almost twice as likely to choose a long-term method when compared with their 15-19 cohorts. Education showed a $60 \%$ decrease in the odds of a woman with secondary education choosing a long-term method relative to a woman with primary education. Thus women with secondary education were more likely to choose short-term methods than their less educated counter parts.

Region had a negative relationship with method choice and emerged as a very significant explanatory variable influencing method choice. There was a $35 \%$ decrease in the odds of a woman from a high contraception region choosing a long-term method when compared with a woman from a region with low contraception uptake. Women from regions of high contraceptive use were thus $65 \%$ more likely to choose short-term methods than those from regions of lower contraception uptake. Thus, women from high contraception regions were more inclined to use short-term methods.

Those from higher wealth status were less likely to use long-term methods of contraception than those of lower wealth. Results show the odds of choosing a long-term method decreased with increased household wealth. Young women of higher wealth emerged as $40 \%$ less likely to choose a long-term method as compared to those from lower wealth status. Women of higher wealth were $60 \%$ more likely to choose short-term methods than those of lower wealth.

There was no notable influence on the choice of a modern method for residence in the regression in all the data sets, suggesting residence could not be used to significantly explain urban-rural variations in contraceptive method choice.

Overall in the regression analysis, age, education, wealth status and type of region emerged as significant predictors of contraceptive method choice.

\section{Discussion}

The study has shown use of modern methods among women aged 15-24 years has been increasing from 2003 but more so from 2008/09. Proportions using modern methods increased almost sixfold between 2008 and 2014. Use of modern methods has been increasing globally and in Kenya in recent years for all women of reproductive age, but more so among those aged 15-24 years, where there are huge numbers of sexually active youth who are initiating contraception. The findings are collaborated by the annual FP2020 reports for Kenya $^{25}$. Other studies had reported rising use of modern methods and more so injectables earlier ${ }^{5,26}$.

Use of long-term methods increased by around four times between 2008/09 and 2014. This is not only a Kenyan phenomenon but a general trend in Sub-Saharan Africa, where successful LARC promotion campaigns and innovative youth sexual and reproductive health programs are increasing the numbers of new acceptors. Implants are now the fastest rising method of contraception among women 15-24, their use more than doubling from 10 to $21 \%$ between 2008/09 and 2014. Rapid increase in the use of implants has been reported recently for several countries, including Kenya, where scale up campaigns have been conducted ${ }^{27,28}$. LARCs are more effective and cheaper in the long term than shorter-acting contraceptives, and are recommended for most women, including adolescents and nulliparous women ${ }^{29}$.

The shift away from short-term methods resulted in declining use of pills and condoms, as shown in Figure 1 and in latter analysis, as declining use of short-term methods which were previously very popular with young women. Condoms are an important dual contraceptive method for prevention against pregnancy and also sexually transmitted infections and HIV/AIDS. They have been previously marketed aggressively to ensure demand creation but shifting priorities of HIV funding have led to fewer campaigns from 2007, which has probably led to their declining use ${ }^{30}$.

As shown in the trend analysis for individual modern methods, implants are the new contraception frontier for women aged 15-24. Other studies have shown implants as increasing their acceptance among young women as efforts to promote them increase. A study in Kenya to promote LARCs among young women showed a major upsurge of implants between 2008 and 2014 with use doubling in the 15-19 age category and increasing by six times among the 20-24-year-old age group ${ }^{31}$.

Regions of lower contraceptive use are surpassing regions of high contraception and are showing potential for major increases in use of modern contraceptives for women aged 15-24 and it is collaborated by FP2020 progress reports. This presents evidence of potential for scaling up modern CPR and achieving the FP2020 targets $^{25}$.

Region was a socio-economic predictor of contraceptive choice in this study in 2008/09 and 2014. However, the classification of regions in terms of contraceptive use, as performed here, has been changing as seen from KDHS 2014 such that regions which previously had lower contraceptive uptake like Western are recording very high uptake of modern contraception especially for LARCs. This is possibly an outcome of highlevel campaigns to promote long-term methods in the whole country but more so in the regions of lower contraceptive use. 
On residence, no distinct variations in method choice are seen in rural or urban areas, suggesting good progress towards equity in accessing methods in both types of residence. Previous studies in Kenya had revealed distinct regional differentials showing the likelihood of using a modern method, more so long-term ones, being higher in urban than rural areas and also higher in regions of high contraception uptake than in regions of lower contraception ${ }^{22}$. In another study in Kenya, residence was also found to influence variations in contraceptive choice ${ }^{5}$.

The findings on the significance of education and wealth status are in line with earlier studies in Kenya that found education and wealth had significant influence on the use of contraception ${ }^{22,23}$. A study in Uganda found similar results ${ }^{24}$. In contrast, other studies on Kenya have not found education and household wealth to be significantly associated to contraceptive use $\mathrm{e}^{32,33}$.

Results have shown that users of modern contraception methods are exhibiting higher education levels in recent years. This is probably a reflection of the heavy investments in education Kenya is making to ensure all children complete primary school and transit to secondary school, and also introducing free primary and secondary education. However, the results of regression with education showed an inverse relationship between education and choice of long-term contraceptive methods in all the data sets. Women with secondary education were 40-70\% less likely to choose long-term methods than those with primary education. The results tally with surprising recent findings in Ghana that women with secondary education were using less effective, short-term and periodic contraception more than effective, long-term, modern methods ${ }^{33,34}$. Questions arise whether they are experimenting with methods, are wary of side effects or are intending to get pregnant.

An interesting finding is that users of more modern contraception were in the lower wealth brackets in 2008/09 and 2014 and users of long-term methods were more in rural areas. This could imply success of family planning campaigns in rural and low-income areas or improved access for women of lower wealth status. Community health workers (CHWs) whose role in expanding contraceptive access has been revitalized work in some of these rural and hard to reach areas where most households are of lower wealth.

As observed in the study results, 15-24-year-old users of modern methods are shifting away from short-term contraceptives towards LARCs, which are more efficient, convenient and offer greater user satisfaction ${ }^{35}$. The shift is more pronounced among women with primary education, from rural areas, lowerwealth households and regions of low contraceptive use. Implants may overtake the injection as the most popular method for this group if the surge in popularity continues.

\section{What do the results mean for Kenya?}

The study results generally indicate success for the aggressive Kenyan family planning program and FP2020 campaigns and existence of great potential for scaling up use of long-term methods among the study group. The phenomenal rise in use of long-term methods observed in the review period will most likely continue due to the ongoing global and local promotion towards LARCs and also because of the momentum of demand from the huge population of 15-24 year olds.

Some program and policy implications arise from the study findings. Young women are shifting towards long-term methods and the use of implants. These are provider-dependent methods and therefore the government needs to invest more in ensuring enough skilled providers to handle insertions/removal as well as counselling on any associated side effects. It is expected that implants, because they are long-term methods, will reduce discontinuations and consequently unintended pregnancies among the young women.

The shift towards long-term methods spells success for the policy on promotion of LARCs for all women, including adolescents. This should increase retention of users of modern methods, protect the gains made in CPR and modern CPR, and contribute towards further reductions in fertility. The cost of LARCs is higher initially, but they are cost-effective in the long term, meaning more funding should be provided towards generating sustainable commodity stocks.

The changing profile of the users of long-term methods, who mostly live in rural and low-income areas, show potential for increased uptake and stepping up the campaigns for LARCs in these areas with more involvement of CHWs.

The emerging shift by secondary educated, wealthier women towards short-term methods calls for targeting of the group to minimise unwanted fertility.

The declining use of condoms raises concern whether the decline will result in increasing incidences of HIV/AIDS and roll back the gains in the fight against HIV/AIDS.

\section{Conclusions}

Results from the study have provided a useful profile of young modern contraceptive users and established a general pattern of their contraceptive use. The study has identified the predictors of contraceptive use among young girls as age, education, household wealth and type of region, and detailed how these factors are changing with time. This information is useful for managers of youth reproductive health programs and could guide interventions to help reduce unintended pregnancies among young girls in Kenya so that girls can stay in school longer and complete their education to desired levels.

The results for the young women, 15-24 years of age, conform to the general shift towards long-term methods for all women of reproductive age, as seen in the recent studies ${ }^{35,36}$. Kenya is an example of family planning policy success but the journey towards replacement level fertility cannot be complete if the 15-24 age group is left behind. More investment towards successful adolescent and youth reproductive health are needed to ensure Kenya takes advantage of the opening of the demographic window and reaps the demographic dividend. 
Young women aged 15-24 are at the centre of these efforts; family planning policy and program managers must ensure they take control of their reproductive health and use contraceptive information and services to their advantage.

Contraception allows young women to make informed choices concerning their reproductive and sexual health, stay in school longer, complete higher levels of education and transition to colleges for labour relevant skills that will enable them optimally contribute to the economy and lead Kenya to achieving the much desired demographic dividend. LARC has potential advantages for these women who wish to delay pregnancy for several years.

To improve the environment for reproductive health and modern contraception for women 15 to 24 years with a view to minimising unintended pregnancies, several interventions can be put in place: 1) Implement fully the National Adolescent Sexual and Reproductive Health Policy, 2015; 2) Initiate age appropriate Life Skills Education (LSE) in all schools; 3) Mainstream youth friendly services into regular services at all health facilities; 4) Expand the range of available method mix for married and unmarried young women and especially the LARCs; and 5) Ensure commodity security by reducing stock outs of commodities.

\section{Data availability}

Source data

The datasets analysed during the current study are available from the MEASURE DHS repository, (http://www.measuredhs.com). Access to the dataset requires registration and is granted to those that wish to use the data for legitimate research purposes. A guide for how to apply for dataset access is available at: https://dhsprogram.com/data/Access-Instructions.cfm.
1. Kenya National Bureau of Statistics: Kenya Demographic and Health Survey 2014. Kenya National Bureau of Statistics and ICF Macro. 2015 Reference Source

2. Kenya National Bureau of Statistics: Kenya Demographic and Health Survey 2008/09. Kenya National Bureau of Statistics and ICF Macro. 2010 Reference Source

3. Kenya National Bureau of Statistics: Kenya Demographic and Health Survey 2003. Kenya National Bureau of Statistics and ICF Macro. 2004. Reference Source

4. Obare F, Birungi $\mathrm{H}$, Chi-Chi U, et al:: Levels, Trends and Determinants of Contraceptive Use among Adolescent Girls in Kenya. Population Council. Aphia II Operations Research Project/ Population Council. 2011. Publisher Full Text

5. Norton M, Chandra-Mouli V, Lane C: Interventions for Preventing Unintended Rapid Repeat Pregnancy among Adolescents: A Review of the Evidence and Lessons from High-Quality Evaluations. Glob Health Sci Pract. 2017; 5(4): 547-570.

PubMed Abstract | Publisher Full Text | Free Full Text

6. Brückner H, Martin A, Bearman PS: Ambivalence and pregnancy: adolescents' attitudes, contraceptive use and pregnancy. Perspect Sex Reprod Health. 2004; 36(6): 248-257.

PubMed Abstract

7. NCPD: State of Kenya Population Report 2017. National Council for Population and Development. 2018

8. NCPD: National Adolescent and Youth Survey. National Council for Population and Development. 2015 Reference Source

9. NCPD: Kenya's Demographic Dividend Roadmap. National Council for Population and Development. 2017. Reference Source

10. Health Policy Project: Impact Now Model: Estimating the Health and Economic Impacts of Family Planning Use. Health Policy Project (HPP), United States Agency for International Development (USAID) and Marie Stopes International (MSI) and Futures Group. Health Policy Project. 2014. Reference Source

11. New J, Cahill N, Stover J, et al.: Levels and trends in contraceptive prevalence, unmet need, and demand for family planning for 29 states and union territories in India: a modelling study using the Family Planning Estimation Tool. Lancet Glob Health. 2017: 5(3): e350-e358. PubMed Abstract | Publisher Full Tex

12. Guttmacher Institute: Adding it Up: Costs and Benefits of Meeting the Contraceptive Needs of Adolescents in Developing Regions. Guttmacher Institute. 2018.

Reference Source

13. GoK: Health Act No. 21 of 2017. Government of Kenya. 2017. Reference Source

14. FP2020: Global Consensus Statement for Expanding Contraceptive Choice
For Adolescent And Youth To Include Long Acting Reversible Contraception FP2020. 2015 Reference Source

15. Temple-Smith M, Sanci L: LARCs as first-line contraception - What can genera practitioners advise young women? Aust Fam Physician. 2017; 46(10): 710-715. PubMed Abstract

16. Guttmacher Institute: Adolescents' Need for and Use of Abortion Services in Developing Countries. Guttmacher Institute. 2016. Reference Source

17. Sedgh G, Finer L, Bankole A, et al:: Adolescent pregnancy, birth, and abortion rates across countries: levels and recent trends. J Adolesc Health. 2015; 56(2): 223-230.

PubMed Abstract | Publisher Full Text | Free Full Text

18. KHRC and RHRA: Teenage Pregnancy and Unsafe Abortion: The Case of Korogocho Slums. Kenya Human Rights Commission and Reproductive Health and Rights Alliance. 2010.

Reference Source

19. Lindberg L, Santelli J, Desai S: Understanding the Decline in Adolescent Fertility in the United States, 2007-2012. J Adolesc Health. 2016; 59(5): 577-583. PubMed Abstract | Publisher Full Text | Free Full Text

20. Chandra-Mouli V, Lane C, Wong S: What Does Not Work in Adolescent Sexual and Reproductive Health: A Review of Evidence on Interventions Commonly Accepted as Best Practices. Glob Health Sci Pract. 2015; 3(3): 333-340. PubMed Abstract | Publisher Full Text | Free Full Text

21. Gribble J, Bremner J: The Challenge of attaining the Demographic Dividend. Policy Brief. Population Reference Bureau. 2012 Reference Source

22. Magadi MA, Curtis SL: Trends and determinants of contraceptive method choice in Kenya. Stud Fam Plann. Population Council. 2003; 34(3): 149-159. PubMed Abstract | Publisher Full Text

23. Kimani M, Njeru M, Ndirangu G: Regional variations in contraceptive use in Kenya: Comparison of Nyanza, Coast and Central Provinces. Afr Popul Stud. 2013; 27(1): 43-52 Publisher Full Text

24. Bbaale E, Mpuga P: Female Education, Contraceptive Use, and Fertility: Evidence from Uganda. Consilience: The Journal of Sustainable Development. Gribble. 2011; 6(1): 20-47. Publisher Full Text

25. FP2020: Annual Progress Report. Kenya. 2015 Reference Source

26. Harbison S, Adetunji J: Contraceptive Choice and Discontinuation in Selected African Countries: A Focus on Injectables. 2009 Reference Source

27. Ross J, Keesbury J, Hardee K: Trends in the contraceptive method mix in low- and middle-income countries: analysis using a new "average deviation" measure. Glob Health Sci Pract. 2015; 3(1): 34-55. PubMed Abstract | Publisher Full Text | Free Full Text 
28. Keyonzo N, Nyachae P, Kagwe P, et al:: From Project to Program: Tupange's Experience with Scaling Up Family Planning Interventions in Urban Kenya. Reprod Health Matters. 2015; 23(45): 103-13.

PubMed Abstract | Publisher Full Text

29. Tsui AO, Brown W, Li Q: Contraceptive Practice in Sub-Saharan Africa. Popul Dev Rev. 2017; 43(Suppl Suppl 1): 166-191. PubMed Abstract | Publisher Full Text | Free Full Text

30. Mann Global Health: The Condom Program Pathway. Bill and Melinda Gates Foundation. 2017. Reference Source

31. Hubacher D, Olawo A, Manduku C, et al:: Preventing unintended pregnancy among young women in Kenya: prospective cohort study to offer contraceptive implants. Contraception. 2012; 86(5): 511-7. PubMed Abstract | Publisher Full Text

32. Fotso J, Izugbara C, Saliku T, et al.: Unintended pregnancy and subsequent use of modern contraceptive among slum and non-slum women in Nairobi, Kenya.
BMC Pregnancy Childbirth. 2014; 14: 224.

PubMed Abstract | Publisher Full Text | Free Full Text

33. Larson C, Stanfors M: Women's Education, Empowerment, and Contraceptive Use in sub-Saharan Africa: Findings from Recent Demographic and Health Surveys. Afr Popul Stud. 2014; 28(2): 1022-1034.

Publisher Full Text

34. Marston C, Renedo A, Nyaaba GN, et al:: Improving the Measurement of Fertility Regulation Practices: Findings from Qualitative Research in Ghana. Int Perspect Sex Reprod Health. 2017; 43(3): 111-119. Perspect Sex Reprod Health. 2017; 43(3):
PubMed Abstract | Publisher Full Text

35. Jacobstein R: Liftoff: The Blossoming of Contraceptive Implant Use in Africa. Glob Health Sci Pract. 2018; 6(1): 17-39.

PubMed Abstract | Publisher Full Text | Free Full Text

36. WHP: Increasing Larc uptake in Kenya through Improved Demand Creation Strategies and Provider Support. Best practices from the WHP 2009-2014. Women's Health Project Best Practices in Kenya. 2015.

Reference Source 


\section{Open Peer Review}

\section{Current Peer Review Status: ? ?}

\section{Version 1}

Reviewer Report 03 May 2022

https://doi.org/10.5256/f1000research.24811.r136459

(c) 2022 Sothornwit J. This is an open access peer review report distributed under the terms of the Creative Commons Attribution License, which permits unrestricted use, distribution, and reproduction in any medium, provided the original work is properly cited.

Jen Sothornwit

Department of Obstetrics and Gynecology, Faculty of Medicine, Khon Kaen University, Khon Kaen, Thailand

This is a secondary analysis from DHS. The study showed the trends in contraceptive methods as well as factors influencing the use in young women.

\section{Introduction:}

It was well written and easy to follow.

Rapid-repeat pregnancy is rather an old term. Short inter-pregnancy interval is a term suggested by society of family planning and other organizations.

Introduction lead to understanding why contraception is imperative. However, analysis was focusing on long- and short-term methods. It would be beneficial if the authors could provide more information on benefits, etc. regarding short- vs long term.

\section{Methods:}

- Was multivariate analysis performed? If yes, provide more information on this analysis (esp. criteria for choosing variable into model, what method was used).

In my opinion, analysis of use vs non-use is important. I am not sure whether this meets the research objective or not.

\section{Results:}

- Why the authors did not provide the OR, adjusted OR for each variable? It would be more informative if they could.

Was the third objective is "utilizing long-term method"?

\section{Discussion:}


The authors did a very good job discussing these results.

Implication practice should move from the last paragraph in the conclusion section to the discussion. More references should be cited to support the proposed strategy.

Strength and limitation should be provided.

\section{Conclusion:}

Some sentences were not directly related to the study results and were over-extrapolated.

Is the work clearly and accurately presented and does it cite the current literature? Yes

Is the study design appropriate and is the work technically sound?

Yes

Are sufficient details of methods and analysis provided to allow replication by others? Yes

If applicable, is the statistical analysis and its interpretation appropriate?

\section{Partly}

Are all the source data underlying the results available to ensure full reproducibility? Yes

Are the conclusions drawn adequately supported by the results? Partly

Competing Interests: No competing interests were disclosed.

Reviewer Expertise: Family planning

I confirm that I have read this submission and believe that I have an appropriate level of expertise to confirm that it is of an acceptable scientific standard, however I have significant reservations, as outlined above.

Author Response 04 May 2022

Margaret Kungu, University of Nairobi, Nairobi, Kenya

Thank you for taking the time to review and give very useful comments on the study. They are very much appreciated and will go a long way towards improving the study. We are reviewing the comments and will endeavor to revise the study guided by them and the comments of the first reviewer and we believe the study will be much better after that for a final print.

Competing Interests: No competing interests were disclosed. 
Reviewer Report 01 April 2020

https://doi.org/10.5256/f1000research.24811.r61496

(c) 2020 Cleland J. This is an open access peer review report distributed under the terms of the Creative Commons Attribution License, which permits unrestricted use, distribution, and reproduction in any medium, provided the original work is properly cited.

\section{John Cleland}

Faculty of Epidemiology and Population Health, London School of Hygieneand Tropical Medicine, London, UK

This paper presents an analysis of method choice among current users of contraception aged 1524 years, using data from the three most recent KDHSs. Descriptive data on method-specific use are shown but the main analysis makes the binary distinction between long- and short-acting methods. In this age group, the main message is that the share of pills and condoms use in overall modern method protection has declined but the share of implants has increased.

The main limitation of the paper is the omission of two key influences on method choice in this age band: marital/cohabitation status and motherhood status. The influence of marital status is critical. The 2014 KDHS shows that about 30\% of sexually active single women aged 15-24 use condoms compared with only $2 \%$ of married women in this age band. Obvious reasons for this difference exist. For young single women sex is often infrequent and clandestine and risks of STI/HIV infection appreciable. Continuous protection from a hormonal method may seem excessive and offers no protection from infection. Young married women are also at risk of STIs but condom use is extremely difficult to sustain within a cohabiting relationship because coital frequency is high and trust is imperative. Without this variable in the analysis, the results are very difficult to interpret. For instance, is the negative association between length of schooling and use of long-acting methods simply a consequence of the fact that well-educated young women are less likely to be married than their less educated counterparts.

The omission of motherhood status is perhaps less crucial but there are reasons to anticipate an influence on method choice. Considerable ethnographic evidence exists that women (single or married) may be reluctant to use a hormonal method before giving birth because of fears that use may jeopardise future fertility. Mothers may also find access to clinical methods easier than nonmothers.

My conclusion is that the analysis should be re-done with marital status as a predictor and at least some exploratory analysis with motherhood status. The small sample sizes for the earlier two KDHSs is a restriction but much more can be done with the much larger sample in the 2014 survey. A really interesting extension would be to make use of Q619 in this survey where women are asked to classify their most recent partner as casual or a regular boyfriend.

The distinction made between short-acting (pills, condoms) and long-acting (Injectables, implants, IUDs) is contentious. Many analysts prefer to classify injectables as short-acting because of high discontinuation. The 2014 KDHS indicates that the all-cause 12 month discontinuation probability for injectables is $31 \%$, lower than pills or condoms at about $43 \%$ but much higher than implants or 
IUDs at 6-8\%. You either need to change your definition or defend it.

Method choice is certainly of interest but the paper would benefit from an introductory table showing trends in use of any modern method among married or sexually active single women aged 15-24. The opening lines of the Discussion refer to a large increase in contraceptive use but your paper presents no data to support this.

\section{Minor points:}

1. Introduction para 1 : It is unclear what $20 \%$ means.

2. Introduction para 3: The mean age of 17 is misleading because it is based only on the minority who have given birth.

3. Introduction para 4: I do not understand what is meant by "The 15-24 year old women take about $15 \%$..."

4. Introduction para 5: Who has claimed that the demographic window opens in 2038? Fertility has been falling in Kenya since the 1980s. You should also explain what is meant by the window.

5. Page 3 penultimate para: Define Larcs here.

6. Methods para1: The definition of current use is confusing.

Is the work clearly and accurately presented and does it cite the current literature? Yes

Is the study design appropriate and is the work technically sound?

Partly

Are sufficient details of methods and analysis provided to allow replication by others? Yes

If applicable, is the statistical analysis and its interpretation appropriate? Yes

Are all the source data underlying the results available to ensure full reproducibility? Yes

Are the conclusions drawn adequately supported by the results? Partly

Competing Interests: No competing interests were disclosed.

Reviewer Expertise: Demography with special interest in fertility and contraception.

I confirm that I have read this submission and believe that I have an appropriate level of 


\section{expertise to confirm that it is of an acceptable scientific standard, however I have} significant reservations, as outlined above.

Author Response 17 Jun 2020

Margaret Kungu, University of Nairobi, Nairobi, Kenya

Thank you Prof. Cleland for the quick, expert, and very useful comments.

I am sorry I did not respond earlier as I thought other reviewer comments would come soon after I respond together.

I will address all the areas you have highlighted in order to give readers a quality paper. I am especially excited about adding the results of Q619/630 on the most recent sexual partner which will be very interesting for youth $\mathrm{RH}$ programs.

Competing Interests: No competing interests were disclosed.

The benefits of publishing with F1000Research:

- Your article is published within days, with no editorial bias

- You can publish traditional articles, null/negative results, case reports, data notes and more

- The peer review process is transparent and collaborative

- Your article is indexed in PubMed after passing peer review

- Dedicated customer support at every stage

For pre-submission enquiries, contact research@f1000.com 